\title{
Diagnostic and Management Challenges of Ciliary Body Tumor in an African-American Patient
}

\author{
Sachin M. Salvi ${ }^{a, b}$ Arun D. Singh ${ }^{b}$

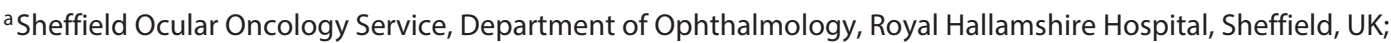 \\ ${ }^{b}$ Department of Ophthalmic Oncology, Cole Eye Institute, Cleveland Clinic Foundation, Cleveland, Ohio, USA
}

\section{Key Words}

Ciliary body tumor - Uveal melanoma - Ciliary body

melanoma African-American population

\begin{abstract}
Purpose: To discuss the diagnostic and management challenges of a ciliary body tumor in an African-American patient. Procedures: Our 52-year-old African-American female patient, referred with a nasal ciliary body tumor in the right eye, underwent investigations including A- and B-scan ultrasonography, Optos fundus photography and fundus fluorescein angiography at clinical consultation. A diagnostic fineneedle aspiration cytology and open flap biopsy were undertaken. Results: Histopathology and cytology confirmed a malignant melanoma, which is extremely rare in the AfricanAmerican population. The patient was treated with brachytherapy with an iodine-131 plaque ensuring adequate coverage of the tumor site but, at the same time, taking special precaution not to disturb the biopsy site. Conclusions: The diagnosis of a ciliary body tumor, especially in an AfricanAmerican patient, can be challenging despite advances in imaging systems, given the multitude of differential diagnoses. Uveal melanomas are extremely rare in African-Americans. On detailed questioning, our patient reported having mixed ancestry, with Caucasian ancestors on the mother's
\end{abstract}

\section{KARGER}

E-Mail karger@karger.com

www.karger.com/oop side and native Indian ancestors on the father's side. Information on true ethnicity should be specifically asked for as it alters the incidence rate. Biopsy provides the only option for a correct diagnosis and for developing a management plan. Fine-needle aspiration biopsy can be diagnostic, though an open flap biopsy is superior as it provides information on tissue architecture and the possibility of immunohistochemistry. Also, with plaque brachytherapy treatment, special care needs to be taken not to disturb the biopsy site to reduce the risk of seeding, and an innovative approach may need to be taken to ensure adequate radiation coverage of these anterior tumors.

(c) 2015 S. Karger AG, Basel

\section{Introduction}

Tumors originating in the ciliary body region can be difficult to diagnose clinically, despite advances in medical imaging, due to the multitude of differential diagnoses. These include pigmented lesions such as melanocytoma [1] and ciliary body melanoma [2], retinal pigment epithelial adenoma [3] (or rarely adenocarcinoma [4]), metastases [5], benign lesions such as schwannoma [6], leiomyoma [7], rare conditions such as hemangiopericytoma $[8]$, medulloepithelioma $[9,10]$ or rarely inflamma- 

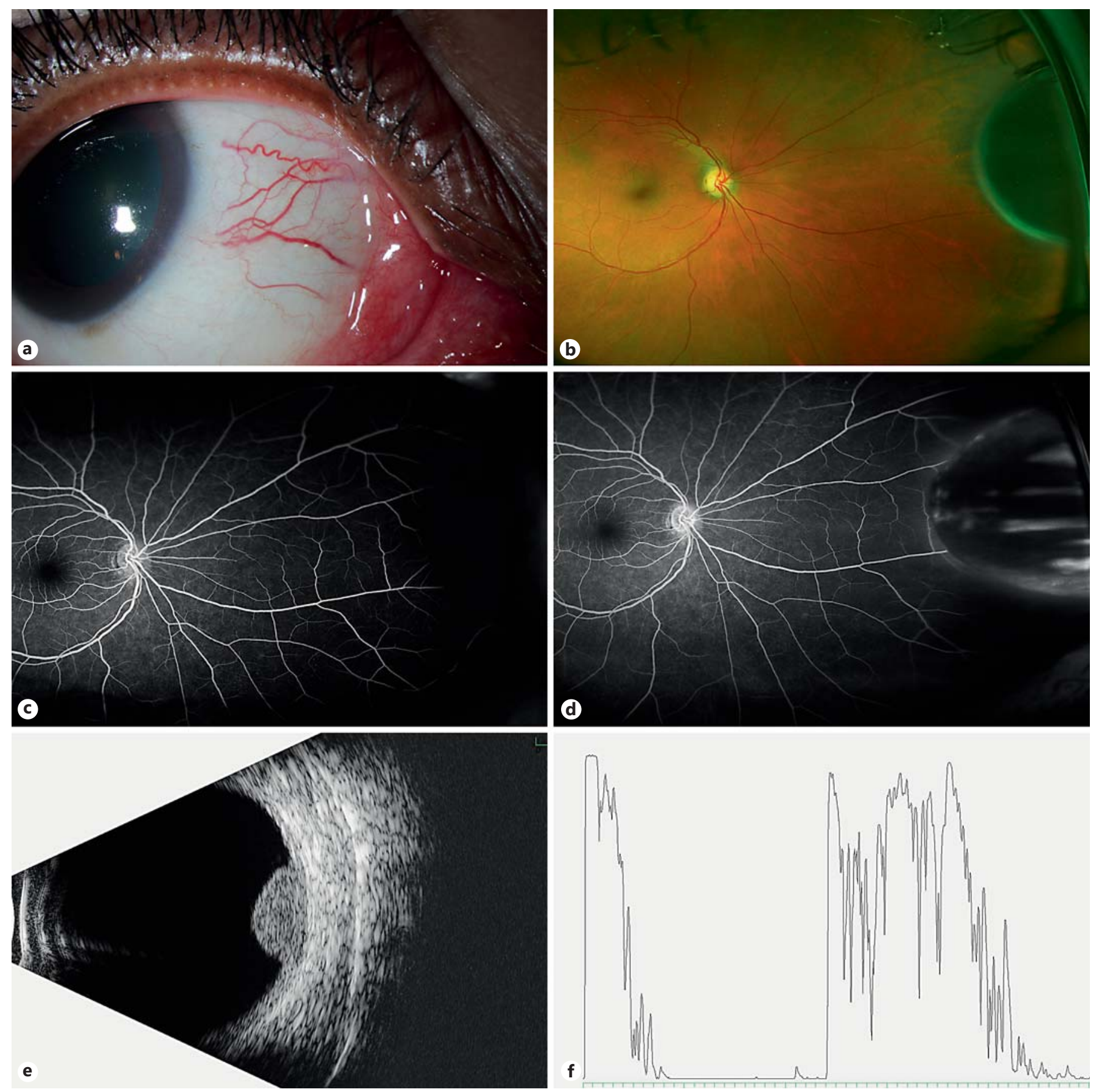

Fig. 1. a External photograph of the right eye demonstrating sentinel vessels. b Wide field photograph of the nasal ciliary body tumor. c Fluorescein angiogram showing tumor hypofluorescence during the early phase of the angiogram. $\mathbf{d}$ Flush of the overlying

ciliary process observed in the late phase of the angiogram. e Transverse B-scan ultrasonography of the lesion at a medium gain. f A-scan ultrasonography showing a slightly irregular structure and medium internal reflectivity. 


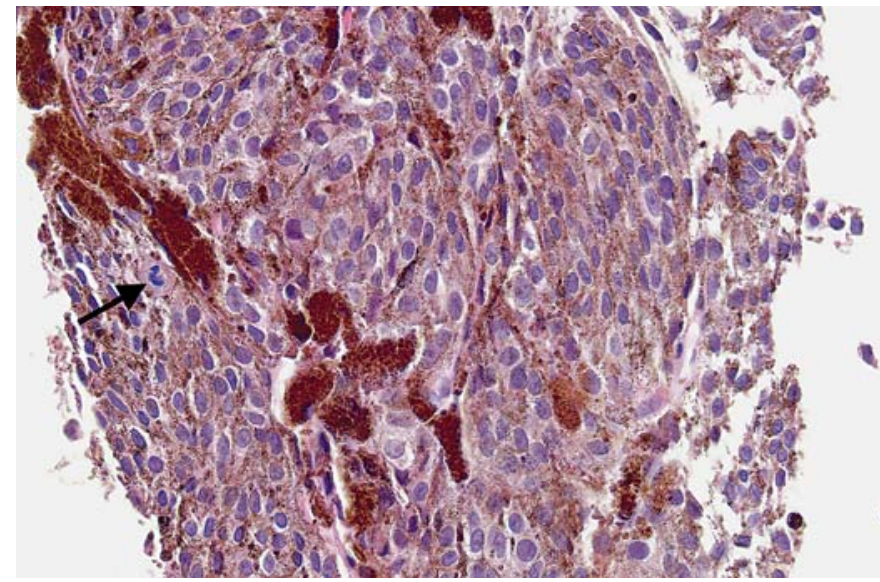

Fig. 2. Histopathological microphotograph showing dense cellular proliferation of epithelioid and plump spindle cells with few mitotic figures, prominent nucleoli and abundant melanin pigment confirming choroidal melanoma. HE. $\times 100$.

tory conditions such as giant sarcoid tumors [11]. A diagnostic biopsy is usually required.

We present the case of an African-American patient who was referred with a ciliary body mass and, on biopsy, was identified to have a ciliary body melanoma.

\section{Case Report}

A 52-year-old African-American patient was referred to the Ophthalmic Oncology Service at Cole Eye Institute with a ciliary body lesion in the nasal aspect of her right eye. She had nonspecific ocular symptoms, and her visual acuity was slightly reduced to 20/25 in her right eye, with her left eye being entirely normal. The family and personal history was noncontributory. On anterior segment examination of her right eye, she was noted to have nasal sentinel vessels (fig. 1a). Dilated fundus examination confirmed a dome-shaped ciliary body mass straddling the ora from the 2 to 4 o'clock position with prominent ciliary processes noted along the anterior surface. The lesion was dark brown in color with no associated retinal detachment, subretinal fluid or exudation (fig. 1b).

On fluorescein angiogram, the tumor maintained hypofluorescence through all the phases of angiography (fig. 1c, d). The lesion had dimensions of $9.5 \times 8.5 \times 3.5 \mathrm{~mm}$ on B-scan ultrasonography (fig. 1e) and medium internal reflectivity without intrinsic vascularity on A-scan ultrasonography (fig. 1f).

Given the diagnostic considerations, after appropriate consent, a standard fine-needle aspiration biopsy (FNAB) was performed. As its yield was thought to be clinically insufficient in spite of two passes with a 25-gauge needle, an open flap incisional biopsy was performed. Both cytology as well as histopathology confirmed a malignant melanoma (fig. 2). Gene expression profiling was done on the FNAB sample that revealed it to be of class 2 .
After discussion with the patient, it was decided to treat the ciliary body melanoma with brachytherapy with an iodine-125 plaque. At surgery, special care was taken not to manipulate the previous biopsy site. The tumor site was identified via transillumination, and a dummy plaque was initially applied to ensure adequate coverage of this nasal tumor. The iodine-125 plaque was then applied after a large relaxing incision had been made under the plica, through which the medial aspect of the plaque was tucked in to ensure stability, while the lateral aspect was anchored at 1 and 5 o'clock positions at the limbus with 5-0 nylon sutures. To cover the exposed plaque, a Tutoplast patch graft was tied into position using 8-0 Vicryl sutures. To minimize postoperative discomfort and eyelid movement over the plaque, a temporary tarsorrhaphy was performed using transmarginal 4-0 silk suture.

The patient has had a good response to plaque therapy with signs of regression of the ciliary body tumor at 3 months of followup and is being serially monitored by liver imaging by an oncologist because of the risk of metastases.

\section{Discussion}

Uveal melanomas are extremely rare in AfricanAmericans $[12,13]$. The annual incidence was shown to be 0.2 per million in an African-American population versus 6.9 per million in a Caucasian population in the study by Margo and McLean [14]. A number of reported cases associate uveal melanomas in African-American patients with oculodermal melanocytosis [15] or melanocytoma $[16,17]$, though there are other reports without the association [18-20]. Our patient described herself as African-American, though on further questioning, she reported mixed ancestry with Caucasian ancestors on the mother's side and native Indian ancestors on the father's side. Information on true ethnicity should be specifically asked for as it alters the incidence rate and has become increasingly important with increasing mixed-race populations.

Our patient had a dome-shaped elevated mass in the ciliary body of her right eye associated with sentinel vessels, suspicious of a ciliary body melanoma. However, her A-scan ultrasonography did not show the classical low internal reflectivity seen in uveal melanomas. Instead, it showed medium internal reflectivity. This is an interesting finding and raises the issue of the definition of typical internal reflectivity of melanomas in African-Americans; the influence of excessive melanin within the tumor needs further investigation.

To identify the underlying diagnosis and direct further management, a biopsy is often required in suspicious atypical cases of ciliary body tumors. FNAB can be diagnostic, although an open flap biopsy is superior as it provides information on tissue architecture and the possibil-
Salvi/Singh 
ity of immunohistochemistry. The use of tissue glue rather than the use of suture to close the partial-thickness flap may be advisable to minimize the potential for local tumor seeding.

During plaque brachytherapy treatment in patients with previous open flap biopsy, special care needs to be taken not to disturb the biopsy site again, to reduce the risk of seeding and metastases. Rather than performing another peritomy to expose the episcleral area in order to apply the plaque (and inadvertently exposing the biopsy site), we recommend placing the plaque over the conjunctiva at the desired position, while tucking one edge of the plaque under a conjunctival incision away from the biopsy site, suturing the other edge directly at the limbus and covering the plaque with a Tutopatch and performing a tarsorrhaphy to ensure adequate and stable coverage of the anterior tumors while maintaining patient comfort.

\section{Statement of Ethics}

We confirm that the subject mentioned in the case report has given informed consent. The study protocol has been approved by the institute's committee on human research. The report does not include any animal experiments.

\section{Disclosure Statement}

The authors declare that there are no conflicts of interest. Also, there are no financial interests.

\section{References}

$>1$ LoRusso FJ, Boniuk M, Font RL: Melanocytoma (magnocellular nevus) of the ciliary body: report of 10 cases and review of the literature. Ophthalmology 2000;107:795-800.

$>2$ Simpson ER: Ciliary body melanoma: a special challenge. Can J Ophthalmol 2004;39: 365-371.

-3 Shields JA, Shields CL, Gündüz K, Eagle RC Jr: Adenoma of the ciliary body pigment epithelium: the 1998 Albert Ruedemann, Sr, memorial lecture, part 1. Arch Ophthalmol 1999; 117:592-597.

4 Grossniklaus HE, Zimmerman LE, Kachmer ML: Pleomorphic adenocarcinoma of the ciliary body. Immunohistochemical and electron microscopic features. Ophthalmology 1990;97:763-768.

5 Ramjiani V, Salvi SM, Rennie IG, Mudhar HS: Supraciliary space breast metastasis. Eye (Lond) 2013;27:673-675.

6 Küchle M, Holbach L, Schlötzer-Schrehardt U, Naumann GO: Schwannoma of the ciliary body treated by block excision. Br J Ophthalmol 1994;78:397-400.
7 Shields JA, Shields CL, Eagle RC Jr, De Potter P: Observations on seven cases of intraocular leiomyoma. The 1993 Byron Demorest Lecture. Arch Ophthalmol 1994;112:521-528.

-8 Brown HH, Brodsky MC, Hembree K, Mrak RE: Supraciliary hemangiopericytoma. Ophthalmology 1991;98:378-382.

$\checkmark 9$ Husain SE, Husain N, Boniuk M, Font RL: Malignant nonteratoid medulloepithelioma of the ciliary body in an adult. Ophthalmology 1998;105:596-599.

10 Kaliki S1, Shields CL, Eagle RC Jr, Vemuganti GK, Almeida A, Manjandavida FP, Mulay K, Honavar SG, Shields JA: Ciliary body medulloepithelioma: analysis of 41 cases. Ophthalmology 2013;120:2552-2559.

-11 Finger PT, Narayana K, Iacob CE, Samson CM, Latkany P: Giant sarcoid tumor of the iris and ciliary body. Ocul Immunol Inflamm 2007; 15:121-125.

12 Margo CE, Mulla Z, Billiris K: Incidence of surgically treated uveal melanoma by race and ethnicity. Ophthalmology 1998;105:10871090.

13 Phillpotts BA, Sanders RJ, Shields JA, et al: Uveal melanomas in black patients: a case series and comparative review. J Natl Med Assoc 1995;87:709-714.
14 Margo CE, McLean IW: Malignant melanoma of the choroid and ciliary body in black patients. Arch Ophthalmol 1984;102:77-79.

15 Shields JA, Shields CL, Naseripor M, et al: Choroidal melanoma in a black patient with oculodermal melanocytosis. Retina 2002;22: 126-128.

16 Heitman KF, Kincaid MC, Steahly L: Diffuse malignant change in a ciliochoroidal melanocytoma in a patient of mixed racial background. Retina 1988;8:67-72.

$>17$ Li HK, Shields CL, Shields JA, Eagle RC Jr, Mason JO 3rd: Iridociliochoroidal melanoma arising from melanocytoma in a black teenager. J AAPOS 2010;14:178-180.

18 Gambrelle J, Dayan G, Baggetto LG, et al: Uveal melanoma in an 18-year-old African black man. Acta Ophthalmol Scand 2005;83: 134-136.

$>19$ Hill JC, Stannard C, Bowen RM: Ciliary body malignant melanoma in a black child. J Pediatr Ophthalmol Strabismus 1991;28:38-40.

20 Kheterpal S, Shields JA, Shields CL, et al: Choroidal melanoma in an African-American albino. Am J Ophthalmol 1996;122:901-903. 